\title{
Extraction of Total Phenolics, Flavonoids and Tannins from Paederia foetida L. Leaves and their Relation with Antioxidant Activity
}

\author{
Shaswat Ojha, Adarsha Raj, Alokesh Roy, Sudipta Roy*
}

\section{Shaswat Ojha, Adarsha Raj, Alokesh Roy, Sudipta Roy $^{*}$}

Department of Botany, University of Kalyani, Kalyani 741235, Nadia, West Bengal, INDIA.

Correspondence

Dr. Sudipta Roy

Department of Botany, University of Kalyani, Kalyani- 741235, Nadia, West Bengal, INDIA.

Phone: +91-9434666930

E-mail: dr.sudiptaroy@gmail.com

\section{History}

- Submission Date: 19-12-2017

- Review completed: 03-01-2017;

- Accepted Date: 18-01-2018

DOI : 10.5530/pj.2018.3.88

Article Available online

http://www.phcogj.com/v10/i3

\section{Copyright}

(C) 2018 Phcog.Net. This is an openaccess article distributed under the terms of the Creative Commons Attribution 4.0 International license.

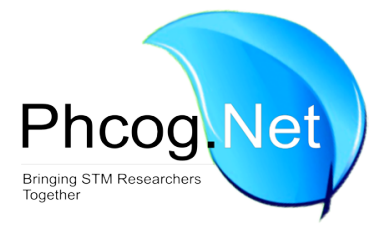

\begin{abstract}
Introduction: Paederia foetida L. is a climbing shrub that possesses several ethnomedicinal uses with immense pharmacologic relevance. Objective: The study aims to determine an efficient extraction condition for phenolic compounds with substantial antioxidant activity. Materials and Methods: Solvent (aqueous, methanol, ethanol and acetone) extracts were made from fresh leaves (FL) and shade dried leaves (SDL) of $P$. foetida with different durations $(12,24,36$ and 48 h). Quantitative estimations of all extracts were made for total phenolic content (TPC), total flavonoid content (TFC) and total tannin content (TTC) along with their total antioxidant activity (TAA). The phenolic contents of different extracts were correlated with their TAA. Extracts with highest phenolic yield and TAA estimates for each solvent were assessed by 2, 2-diphenyl-1-picrylhydrazyl (DPPH), 2, 2'-azinobis-3-ethylbenzthiazoline-6sulfonic acid (ABTS), superoxide (SO) and ferric reducing antioxidant power (FRAP) assays. Results: Methanol exhibited the highest extraction ability for TPC, TFC and TAA while aqueous extractions are superior for TTC. The maximum estimates of all the studied components are noted at $48 \mathrm{~h}$. Mostly, extracts of SDL are superior to FL. TPC and TFC are interrelated between themselves as well as showed positive and significant correlation with TAA. The antioxidant assays (DPPH, ABTS, SO and FRAP) reveal higher antioxidant activity with methanolic extracts compared to other studied solvents. Conclusion: The study highlights antioxidant properties of phenolics, particularly flavonoids in P. foetida, which can be further explored for its pharmacological importance.

Key words: Antioxidants, Extraction conditions, Fresh and shade dried leaves, Paederia foetida, Polyphenols.
\end{abstract}

\section{INTRODUCTION}

Paederia foetida L., belonging to the family Rubiaceae is a perennial climbing shrub, extensively used in folk medicine for the remedy of stomach disorders, gastritis, indigestion, rheumatic pain, improvement of liver and kidney function ${ }^{1,2,3}$ among others. The species possesses antiarthitic, ${ }^{3}$ anti-inflammatory, ${ }^{4}$ hepatoprotective, ${ }^{5}$ antitussive, ${ }^{6}$ antidiarrhoeal, ${ }^{7}$ activities and also manifests aphrodisiac potentiality by increasing testosterone levels in experimental rats. ${ }^{8}$ P. foetida is reported to consist of different phytoconstituents like iridoid glycosides (asperuloside, scandoside and paederoside), volatile oils (linalool, geraniol, $a$-terpineal), triterpenoids (urosolic acid, oleanolic acid) $\beta$-sitosterol, arachidic acid $^{1,9,10}$ which are implicated for diverse bioactivities. ${ }^{11,12,13}$ It also contains alkaloids (paederine a and b), flavonoids and high proportion of mineral elements. ${ }^{1,14}$ However, reports on phenolics in the species are rather meagre. ${ }^{1}$ The foetid smell of $P$. foetida is due to release of methyl-mercaptan from the injured plant tissues following enzymatic cleavage of paederoside. ${ }^{15}$
Plant phenolics, an important class of secondary metabolites, consist of structurally heterogeneous group ranging from simple phenolic acids to much complex polymeric structure like tannins. ${ }^{16}$ Flavonoids are the most abundant phenolics in plants that exhibit diverse bioactivities mostly due to their antioxidant potential. The plant derived antioxidants are significant due to their ability to inhibit or delay oxidative damages caused during many degenerative

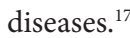

Polyphenols are extracted from plants by various ways differing in solvent composition and conditions. Among the different extraction methods, solvent extractions by cold maceration are widely used due to its convenience and efficacy. ${ }^{18}$ Efficient extraction of bioactive phytochemicals involves a wide range of solvents of varying polarities of which solvents with higher polarities are preferable for phenolics. ${ }^{16}$ Among several conditions that control extraction efficacy, extraction time appreciably influence quality and quantity of the extracts. ${ }^{19}$

Cite this article: Ojha S, Raj A, Roy A, Roy S. Extraction of Total Phenolics, Flavonoids and Tannins from Paederia foetida L. Leaves and their Relation with Antioxidant Activity. Pharmacog J. 2018;10(3):541-7. 
The present study highlights extraction of total phenolics, flavonoids and tannins under different solvents (water, methanol, ethanol, acetone) at different durations $(12,24,36$ and $48 \mathrm{~h})$ using fresh and shade dried leaves of $P$. foetida. Furthermore, an interrelationship is ascertained between/among the phenolic compounds and antioxidant activity. The objective of the work is to determine an efficient extraction condition for phenolics with higher antioxidant activity in the studied plant species.

\section{MATERIALS AND METHODS}

\section{Chemicals}

Folin-Ciocalteau's (FC) reagent, aluminum chloride $\left(\mathrm{AlCl}_{3}\right)$, ammonium molybdate, ascorbic acid, ethylenediaminetetraacetic acid (EDTA), ferric chloride $\left(\mathrm{FeCl}_{3}\right)$, ferrous sulphate $\left(\mathrm{FeSO}_{4} \cdot 7 \mathrm{H}_{2} \mathrm{O}\right)$, potassium acetate, potassium ferricyanide, potassium persulphate, riboflavin, sodium nitrite $\left(\mathrm{NaNO}_{2}\right)$ and sulfuric acid were obtained from Merck, India. $\mathrm{DPPH}, \mathrm{ABTS}$, gallic acid, quercetin, nitro blue tetrazolium (NBT), tannic acid and 2, 4, 6-tripyridyl-s-triazine (TPTZ) were purchased from Sigma-Aldrich, (St. Louis, MO, USA). All other reagents were of analytical grade.

\section{Plant materials}

Healthy and mature leaves of Paederia foetida L. were collected in the month of September 2015 from the medicinal plant garden of Department of Botany, University of Kalyani, Kalyani $\left(22.9750^{\circ} \mathrm{N}\right.$ and $88.4344^{\circ} \mathrm{E}$; $9.75 \mathrm{~m}$ above mean sea level), Nadia, West Bengal, India. The plant species was identified following suitable manual. ${ }^{20}$ and an authentic voucher specimen was preserved at the herbarium repository of Department of Botany, University of Kalyani.

\section{Extract Preparation}

The extractions were made from fresh leaves (FL) and shade dried leaves (SDL). The SDL were obtained by drying the FL at room temperature $\left(27 \pm 2^{\circ} \mathrm{C}\right)$ for $10 \mathrm{~d}$ in shade $(2 \mathrm{~g}$ FL were dried to $1 \mathrm{~g}$ SDL). The FL were washed with deionised water to remove the adherent debris and $2 \mathrm{~g}$ leaves were cut into small pieces and extracted with double distilled water (aqueous), methanol, ethanol, and acetone for 12, 24, 36 and $48 \mathrm{~h}$. The SDL samples $(1 \mathrm{~g})$ were pulverised by a mechanical grinder and extracted similarly. During solvent extraction by cold maceration the sample to solvent ratio was kept constant at 1:20 (w/v). The extractions were made at room temperature with occasional shaking and subsequently the extracts were filtered through Whatman No 1 filter paper to remove the plant remains. The filtrates were concentrated under reduced pressure using rotary vacuum evaporator at $50^{\circ} \mathrm{C}$ (Büchi, Rotavapor R-II-HB; V-700; Switzerland), dried, estimated the final yield and stored at $4^{\circ} \mathrm{C}$ for further study.

\section{Determination of total phenolic content (TPC)}

TPC was determined by modified FC method. ${ }^{21}$ The extracts $(0.5 \mathrm{ml}$; $1 \mathrm{mg} / \mathrm{ml}$ stock solution) were mixed with $0.5 \mathrm{ml}$ of distilled water and $1 \mathrm{ml}$ of FC reagent (pre-diluted, 10 times, with distilled water) and incubated for $5 \mathrm{~min}$ at room temperature $\left(27 \pm 2^{\circ} \mathrm{C}\right)$. After incubation, $2 \mathrm{ml}$ of $700 \mathrm{mM}$ sodium carbonate was added in the reaction mixtures, mixed and kept in dark for $45 \mathrm{~min}$ at room temperature. The absorbances of the samples were measured at $765 \mathrm{~nm}$ using a UV-Vis spectrophotometer (CECIL, CE 7200; Cambridge, UK). A calibration curve was prepared using standard solutions of gallic acid ranging from 10 to $80 \mu \mathrm{g} / \mathrm{ml}$ $\left(r^{2}=0.983\right)$. The amount of phenolics in different extracts was calculated from the calibration curve and was expressed as mg gallic acid equivalent (GAE) per gm of FL and SDL.

\section{Determination of total flavonoid content (TFC)}

TFC were quantified according to the method of Chang et al. ${ }^{22}$ with minor modifications. The samples $(0.5 \mathrm{ml}$ extract; $1 \mathrm{mg} / \mathrm{ml}$ stock $)$ were mixed with $1.5 \mathrm{ml}$ distilled water and $0.2 \mathrm{ml} 5 \% \mathrm{NaNO}_{2}$ and the resultant solution could stand for $2 \mathrm{~min}$ at room temperature $\left(27 \pm 2^{\circ} \mathrm{C}\right)$. Subsequently, $0.2 \mathrm{ml}$ of $10 \% \mathrm{AlCl}_{3}$ in ethanol and $0.6 \mathrm{ml} 1 \mathrm{~N}$ sodium hydroxide were added successively with vortexing in each step. The samples were incubated in dark at room temperature for $10 \mathrm{~min}$ and the absorbance was measured at $510 \mathrm{~nm}$ using a spectrophotometer. The amount of total flavonoid in the samples was quantified from the calibration curve of quercetin (ranging from 10 to $400 \mu \mathrm{g} / \mathrm{ml} ; \mathrm{r}^{2}=0.990$ ) and was expressed as mg quercetin equivalent (QE) flavonoid per $g$ of leaf samples (FL and SDL).

\section{Determination of total tannin content (TTC)}

TTC were estimated using the modified method of Price and Butler. ${ }^{23}$ The extracts $(500 \mu \mathrm{l} ; 1 \mathrm{mg} / \mathrm{ml}$ stock solution) were mixed with distilled water $(8 \mathrm{ml}), 0.5 \mathrm{ml}$ of $0.1 \mathrm{M} \mathrm{FeCl}_{3}$ and $0.5 \mathrm{ml}$ of $8 \mathrm{mM}$ potassium ferricyanide sequentially and incubated at room temperature $\left(27 \pm 2^{\circ} \mathrm{C}\right)$ for $10 \mathrm{~min}$. The absorbance was measured at $720 \mathrm{~nm}$ using a spectrophotometer. Reagent blanks for each solvent were prepared similarly without adding the sample. The amount of total tannin in the samples was quantified from a calibration curve of tannic acid (ranging from 1.5 to $20 \mu \mathrm{g} / \mathrm{ml} ; \mathrm{r}^{2}=0.999$ ) and expressed as $\mathrm{mg}$ tannic acid equivalent (TAE) per $g$ of leaf samples (FL and SDL).

\section{Estimation of total antioxidant activity (TAA)}

TAA of the extracts was determined using phospho-molybdenum method. ${ }^{24}$ with modifications. The reaction mixture consisted of $0.5 \mathrm{ml}$ sample (from $1 \mathrm{mg} / \mathrm{ml}$ stock solution), $0.5 \mathrm{ml}$ distilled water and $3 \mathrm{ml}$ reagent solution $(0.6 \mathrm{M}$ sulfuric acid, $28 \mathrm{mM}$ sodium phosphate and $4 \mathrm{mM}$ ammonium molybdate). The resultant mixtures were incubated in a water bath at $90 \pm 1^{\circ} \mathrm{C}$ for $90 \mathrm{~min}$, cooled down to room temperature $\left(27 \pm 2^{\circ} \mathrm{C}\right)$ and the absorbance were recorded at $695 \mathrm{~nm}$ using a spectrophotometer. The estimates were done using a calibration curve of ascorbic acid (ranging from 10 to $140 \mu \mathrm{g} / \mathrm{ml} ; \mathrm{r}^{2}=0.979$ ) and expressed as $\mathrm{mg}$ ascorbic acid equivalent (AAE) per $g$ of leaf samples (FL and SDL).

\section{$D P P H$ radical scavenging assay}

The antioxidant activity of the superior extracts (FL and SDL; all solvents: $48 \mathrm{~h}$ ) of different solvents was determined by measuring the reducing ability of antioxidants towards $\mathrm{DPPH} \cdot$ radical. The radical scavenging assay was carried out following Brand Williams et al. ${ }^{25}$ with modifications. An aliquot $(50 \mu \mathrm{l})$ of extract of different concentrations $(50 \mu \mathrm{g} / \mathrm{ml}$ to $1000 \mu \mathrm{g} / \mathrm{ml}$ ) was added to $1.2 \mathrm{ml}$ of $6 \times 10^{-5} \mathrm{M} \mathrm{DPPH}$ solution. The ingredients were mixed by vortexing, incubated at dark for $15 \mathrm{~min}$ at room temperature $\left(27 \pm 2^{\circ} \mathrm{C}\right)$ and the absorbance was measured at $517 \mathrm{~nm}$ against a blank (methanol) using a spectrophotometer. Results were expressed as percentage scavenging activity of the $\mathrm{DPPH}^{\bullet}$ radical which was calculated according to the following equation:

$$
\text { Scavenging activity }(\%)=\frac{A_{\text {control }}-A_{\text {sample }}}{A_{\text {control }}} \times 100
$$

Where, $\mathrm{A}_{\text {control }}$ and $\mathrm{A}_{\text {sample }}$ are the absorbance of the control and the test sample, respectively. The $50 \%$ scavenging of the DPPH radical $\left(\mathrm{IC}_{50}\right)$ was estimated from a graphical plot where percent scavenging (inhibition) was plotted against varying concentrations of an extract.

\section{ABTS radical scavenging assay}

The radical scavenging activity of the extracts was determined by ABTS * radical decolourization assay described by Re et al. ${ }^{26}$ with minor modifications. The $\mathrm{ABTS}^{\bullet+}$ radical was generated by reacting $7 \mathrm{mM}$ ABTS in deionized water with $2.45 \mathrm{mM}$ potassium persulfate, incubated in the dark for $16 \mathrm{~h}$ at room temperature $\left(27 \pm 2^{\circ} \mathrm{C}\right)$. Prior to use, the ABTS solution was diluted with ethanol to get an absorbance of $0.700 \pm 0.02$ 
at $734 \mathrm{~nm}$. The antioxidant assay was performed by adding $50 \mu \mathrm{l}$ of the sample (in varying concentrations ranging from 100 to $1000 \mu \mathrm{g} / \mathrm{ml}$ ) in $950 \mu \mathrm{l}$ of the diluted ABTS solution and the absorbance was measured at $734 \mathrm{~nm}$. The sample absorbance was compared with a blank (50 $\mu \mathrm{l}$ ethanol and $950 \mu \mathrm{l}$ of diluted ABTS solution) to detect spontaneous degradation of ABTS, if any, without antioxidant. The percent scavenging activity and $\mathrm{IC}_{50}$ value of the samples were determined similarly that was described for DPPH scavenging assay.

\section{Superoxide (SO) scavenging activity}

The SO radicals were generated by modified method based on Beauchamp and Fridovich. ${ }^{27}$ The assay was based on the potentiality of the samples to inhibit blue formazan formation by scavenging the superoxide radical generated in riboflavin-light-NBT system. ${ }^{28}$ The samples of different concentrations were prepared in $50 \mathrm{mM}$ sodium phosphate buffer ( $\mathrm{pH}$ 7.6). The total volume of reaction mixture was $3 \mathrm{ml}$ which was prepared by sequential addition of $1 \mathrm{ml}$ of sample solution, $1.8 \mathrm{ml}$ of $50 \mathrm{mM}$ sodium phosphate buffer $\mathrm{pH}$ 7.6, $20 \mu \mathrm{l} 2.66 \mathrm{mM}$ riboflavin, $80 \mu \mathrm{l} 12 \mathrm{mM}$ EDTA and $100 \mu \mathrm{l} 1.22 \mathrm{mM}$ NBT. The photo-induced reactions were initiated by illuminating the reaction mixtures with a $20 \mathrm{~W}$ luminous bulb within an aluminium lined box for $90 \mathrm{sec}$ at room temperature. The non-illuminated reaction mixture was used as blank. After completion of reaction, the absorbances were measured at $590 \mathrm{~nm}$. The $\mathrm{IC}_{50}$ values were determined from the percent SO radical scavenging and that was obtained from the formula represented in previous sections.

\section{Determination of ferric reducing antioxidant potential (FRAP)}

The ferric reducing power of extracts was determined by a modified method of Benzie and Strain. ${ }^{29}$ The method relies on reduction of colourless ferric complex $\left(\mathrm{Fe}^{3+}\right)$ to a blue-coloured ferrous complex $\left(\mathrm{Fe}^{2+}\right)$, at low $\mathrm{pH}$, by electron donating antioxidants. The FRAP reagent was prepared fresh by mixing 10 volumes of $300 \mathrm{mM}$ sodium acetate buffer ( $\mathrm{pH}$ 3.6) with 1 volume of $10 \mathrm{mM}$ TPTZ in $40 \mathrm{mM}$ hydrochloric acid and with 1 volume of $20 \mathrm{mM} \mathrm{FeCl}_{3}$. Following preparation, the reagent was pre-warmed at $37^{\circ} \mathrm{C}$ before use. The reaction mixture, consisted of $300 \mu \mathrm{l}$ of extract preparations with $2.7 \mathrm{ml}$ of FRAP reagent, was incubated at $37^{\circ} \mathrm{C}$ for $5 \mathrm{~min}$ and absorbance were measured at $594 \mathrm{~nm}$. FRAP values were expressed as $\mathrm{mM} \mathrm{Fe}^{2+} / \mathrm{mg}$ of sample and calculated using a calibration curve of ferrous sulphate $\left(\mathrm{r}^{2}=0.981\right)$ of different concentrations.

\section{Statistical analysis}

Critical difference $(\mathrm{CD})$ at 0.05 probability level was performed to assess the significant level, if any, between and among the estimates of phenolics (TPC, TFC, and TTC) and TAA for different extraction conditions. $\mathrm{CD}$ at 0.05 probability level was also ascertained between/among the estimates of different antioxidant assays (DPPH, ABTS, SO and FRAP) in FL and SDL (48 h, all solvents) to assess significant variation, if any. Pearson correlation coefficient ( $\mathrm{r}$ ) was determined between the studied attributes like TPC, TFC, TTC and TAA considering extraction conditions at 47 degrees of freedom to ascertain whether there exists any interrelationship between and among them or not.

\section{RESULTS}

\section{Extraction efficacy of phenolic components}

The extraction efficacy of TPC (GAE/g; FL and SDL), TFC (QE/g; FL and SDL) and TTC (TAE/g; FL and SDL) from leaf samples (FL and SDL) under different extraction conditions (solvents used and duration of extraction) is presented in Table 1 and Figure 1. Results demonstrate that maximum quantity of TPC (FL: $4.090 \pm 0.11$; SDL: $4.957 \pm 0.17$ ) and TFC (FL: 28.002 \pm 1.86 ; SDL: 71.221 \pm 3.08) is recorded following methanolic extraction for $48 \mathrm{~h}$ duration. The yield of TPC and TFC is found to enhance in a time dependent manner. The quantified amount of
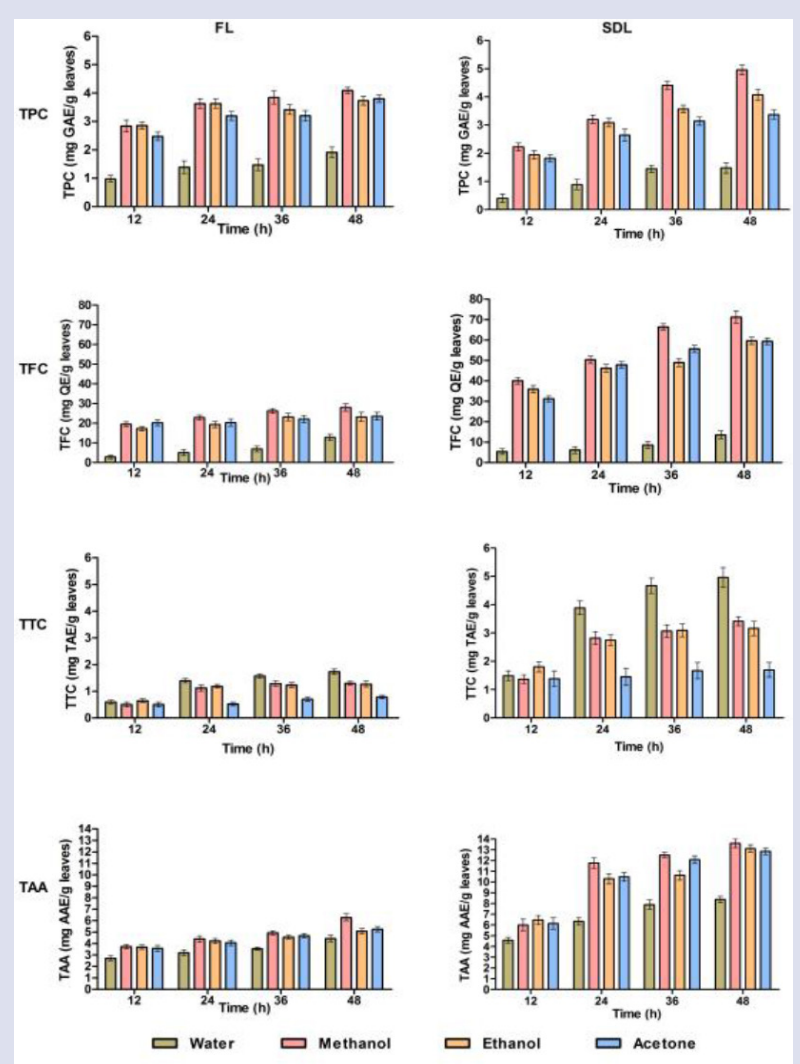

Figure 1: Phenolic yield (TPC, TFC and TTC) and total antioxidant activity (TAA) in FL and SDL of $P$. foetida.

TFC is mostly two-fold higher in all cases in SDL than FL. However, the estimates noted in TPC are rather higher mostly in FL than SDL expecting for $36 \mathrm{~h}$ and $48 \mathrm{~h}$ durations with methanolic and ethanolic extractions. Irrespective of the leaf types used, quantity of phenolics (TPC and TFC) mostly varied significantly $(\mathrm{p}<0.05)$ between/among the solvents used, and durations of extraction. For both TPC and TFC the efficacy of extraction is in the order of methanol $>$ acetone $>$ ethanol for FL and methanol $>$ ethanol $>$ acetone for SDL. Results highlight that maximum yield of TTC is obtained following aqueous extraction for $48 \mathrm{~h}$ in both FL (1.733 \pm 0.10$)$ and SDL (4.961 \pm 0.35$)$ with significant enhancement in SDL than FL. Thus, irrespective of the solvents used, extraction efficiency of TPC, TFC, and TTC is best in $48 \mathrm{~h}$, SDL.

Correlation analyses (Table 2) reveal positive and significant interrelationship only between TPC and TFC (FL: $\mathrm{p}<0.001, \mathrm{r}=0.961$, DF 47; SDL: $\mathrm{p}<0.001, \mathrm{r}=0.950$, DF 47).

\section{Antioxidant activity of extracts}

The TAA (AAE /g; FL and SDL) activity of $P$. foetida leaf extracts is also depicted in Table 1 and Figure 1. The maximum activity of TAA in FL $(6.273 \pm 0.31)$ and SDL (13.587 \pm 0.39$)$ is recorded following extraction with methanol for $48 \mathrm{~h}$. For both the leaf types, methanolic extraction show significantly $(\mathrm{p}<0.05)$ higher activities than the other solvent extractions for 24,36 and $48 \mathrm{~h}$ durations. At $12 \mathrm{~h}$ duration, TAA activity is highest with ethanolic extraction. In all cases, SDL show pronounced ( $>2$-fold increase mostly) TAA activity than FL.

Correlation studies (Table 2) reveal that TAA is positively and significantly associated with TPC (FL: $\mathrm{p}<0.001, \mathrm{r}=0.797, \mathrm{DF}$ 47; SDL: 


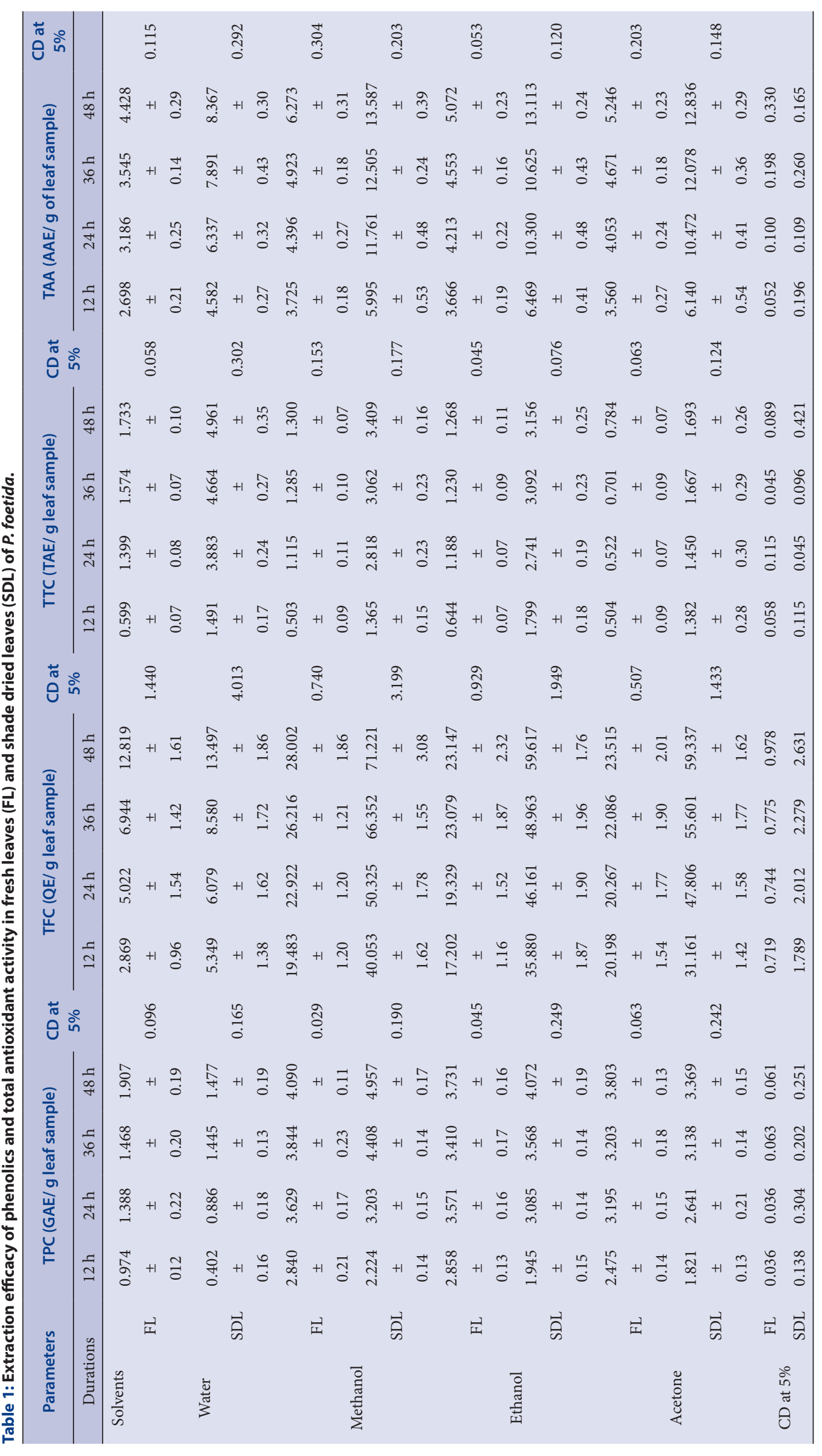



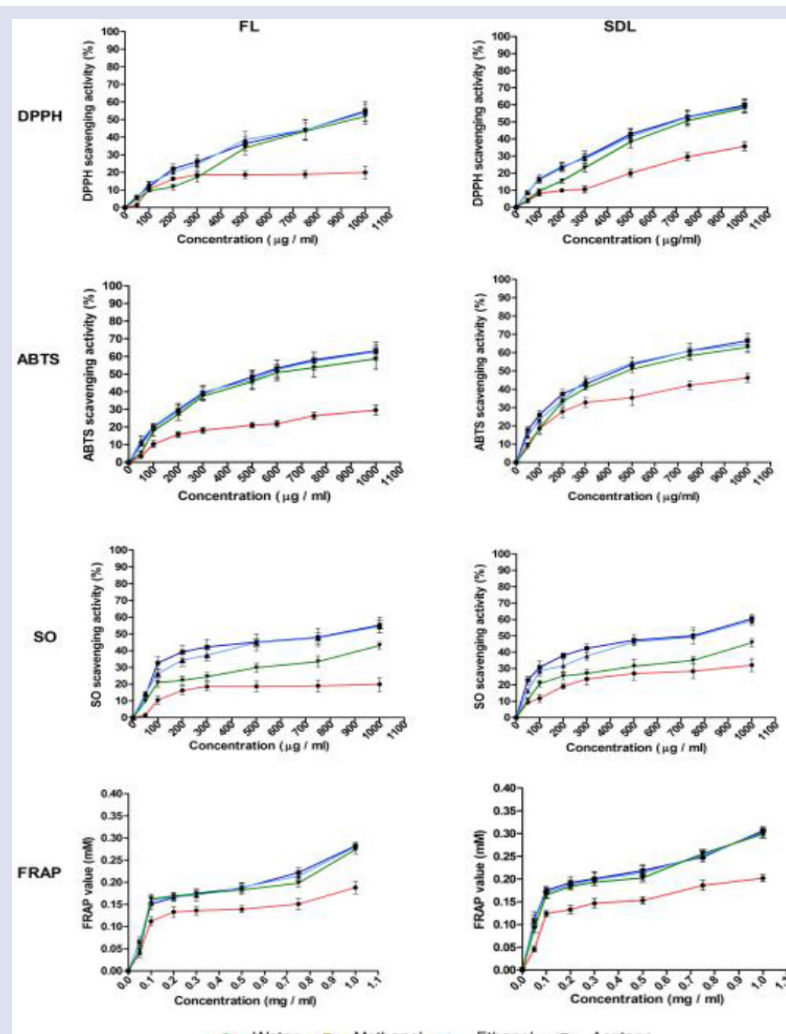

- Water $\rightarrow$ Methanol \& Ethanol $\rightarrow$ Acetone

Figure 2: Radical scavenging (DPPH, ABTS and SO) and reducing power (FRAP) activity of extracts from FL and SDL using different solvents at $48 \mathrm{~h}$ duration.

$\mathrm{p}<0.001, \mathrm{r}=0.900, \mathrm{DF} 47)$ and TFC (FL: $\mathrm{p}<0.001, \mathrm{r}=0.799$, DF 47; SDL: $\mathrm{p}<0.001, \mathrm{r}=0.845$, DF 47).

From extraction efficacy it appears that $48 \mathrm{~h}$ duration is most productive for TPC, TFC, TTC yield and TAA activity in both FL and SDL for all the solvents studied. The data presented in Table 3 and Figure 2 documents antioxidant (DPPH, ABTS, SO and FRAP) activities ascertained from FL and SDL extracts at $48 \mathrm{~h}$. The Figure 2 depicts higher antioxidant activity in SDL compared to FL in all cases with maximum efficacy in methanolic extracts followed by ethanol, acetone and water. The $\mathrm{IC}_{50}$ value is determined for DPPH, ABTS and SO by the radical scavenging activity of the antioxidants present in the extracts. The lower $\mathrm{IC}_{50}$ values indicate
Table 2: Correlation analysis showing relationship between the attributes.

\begin{tabular}{ccccc}
\hline Parameters & TPC & TFC & TTC & TAA \\
\hline \multirow{2}{*}{ TPC } & 1.000 & & & \\
& $\mathbf{1 . 0 0 0}$ & & & \\
\multirow{2}{*}{ TFC } & $0.961^{* * *}$ & 1.000 & & \\
& $\mathbf{0 . 9 5 0 ^ { * * * }}$ & $\mathbf{1 . 0 0 0}$ & & \\
TTC & -0.062 & -0.123 & 1.000 & \\
& $\mathbf{0 . 0 1 9}$ & $\mathbf{- 0 . 2 5 9}$ & $\mathbf{1 . 0 0 0}$ & \\
\multirow{2}{*}{ TAA } & $0.797^{* * *}$ & $0.799^{* * *}$ & 0.225 & 1.000 \\
& $\mathbf{0 . 9 0 0}^{* * *}$ & $\mathbf{0 . 8 4 5}$ & $\mathbf{0 . 1 5 2}$ & $\mathbf{1 . 0 0 0}$ \\
\hline
\end{tabular}

*** Significant at 0.001 probability level.

Bold values represent SDL.

higher scavenging efficiency and with enhanced antioxidant potentiality. The $\mathrm{IC}_{50}$ value could not be determined precisely in aqueous extracts of $\mathrm{DPPH}, \mathrm{ABTS}$ and $\mathrm{SO}$ and that of acetone extracts of $\mathrm{SO}$ as it is above the maximum concentration $(1000 \mu \mathrm{g} / \mathrm{ml})$ used in the present study (Table 3 ). The DPPH assay data represent lower $\mathrm{IC}_{50}$ values $(740.60 \pm 36.58$ to $786.97 \pm 39.23)$ for SDL than FL (859.20 38.65 to $902.30 \pm 37.73)$ following methanol, ethanol and acetone extractions. Similar trend is also followed in ABTS (SDL: $538.97 \pm 43.64$ to $609.63 \pm 49.37$; FL: $629.80 \pm 44.62$ to $690.03 \pm 53.62$ ) and SO (SDL: $673.93 \pm 58.91$ to $726.83 \pm 48.64$; FL: $769.03 \pm 33.40$ to $789.13 \pm 48.88)$. Although significant $(\mathrm{p}<0.05)$ variation is noted in detectable $\mathrm{IC}_{50}$ values between $\mathrm{SDL}$ and $\mathrm{FL}$, variations are not significant among the different solvents in either of the leaf types. In FRAP assay, higher values $(\mathrm{mM} / \mathrm{mg})$ are indicative of better antioxidant activity. Excepting aqueous extracts (FL: $0.626 \pm 0.04$; SDL: $0.673 \pm 0.02$ ), FRAP values are higher in other solvents with a maximum in methanol extracts (FL: $0.940 \pm 0.04$; SDL: $1.020 \pm 0.03$ ). The FRAP values are relatively higher and mostly significant $(\mathrm{p}<0.05)$ in SDL than FL.

\section{DISCUSSION}

The present study reaffirms that the leaves of $P$. foetida are rich source of phenolics as evinced from quantitative estimation of TPC, TFC and TTC. ${ }^{30,31}$ Solvent extraction following maceration and enhanced duration softens and breaks the cell wall to release soluble phytochemicals. The present investigation demonstrates that the amount of phenolics is increased with time; with a maximum at $48 \mathrm{~h}$. Estimates of TPC and TFC are higher with methanol compared to other studied solvents. Methanol is commonly used solvent for its higher polarity with higher dielectric

Table 3: Results showing antioxidant activity in FL and SDL in different solvents at $48 \mathrm{~h}$ duration.

\begin{tabular}{|c|c|c|c|c|}
\hline \multirow{2}{*}{ Samples } & \multicolumn{3}{|c|}{$\mathrm{IC}_{50}$ value $(\mu \mathrm{g} / \mathrm{ml})$} & \multirow{2}{*}{$\begin{array}{c}\text { FRAP value } \\
\text { (mM)/ mg } \\
\text { sample }\end{array}$} \\
\hline & DPPH & ABTS & So & \\
\hline FL $48 \mathrm{~W}$ & $>1000$ & $>1000$ & $>1000$ & $0.626 \pm 0.04$ \\
\hline FL $48 \mathrm{M}$ & $859.20 \pm 38.65$ & $629.80 \pm 44.62$ & $769.03 \pm 33.40$ & $0.940 \pm 0.04$ \\
\hline FL $48 \mathrm{E}$ & $890.77 \pm 30.99$ & $633.33 \pm 55.16$ & $789.13 \pm 48.88$ & $0.933 \pm 0.04$ \\
\hline FL $48 \mathrm{~A}$ & $902.30 \pm 37.73$ & $690.03 \pm 53.62$ & $>1000$ & $0.912 \pm 0.05$ \\
\hline SDL $48 \mathrm{~W}$ & $>1000$ & $>1000$ & $>1000$ & $0.673 \pm 0.02$ \\
\hline SDL $48 \mathrm{M}$ & $740.60 \pm 36.58$ & $538.97 \pm 43.64$ & $673.93 \pm 58.91$ & $1.020 \pm 0.03$ \\
\hline SDL $48 \mathrm{E}$ & $751.17 \pm 29.86$ & $556.47 \pm 39.69$ & $726.83 \pm 48.64$ & $1.007 \pm 0.03$ \\
\hline SDL $48 \mathrm{~A}$ & $786.97 \pm 39.23$ & $609.63 \pm 49.37$ & $>1000$ & $0.998 \pm 0.03$ \\
\hline $\mathrm{CD}$ at $5 \%$ & 53.72 & 82.87 & 75.28 & 0.06 \\
\hline
\end{tabular}


Ojha et al.: Phenolics in P. foetida with antioxidant activity

constant $\left(32.6\right.$ at $\left.20^{\circ} \mathrm{C}\right)$ for extraction of phenolics ${ }^{32}$ from different plant species namely, Amomum, ${ }^{33}$ Thymus, ${ }^{34}$ Moringa ${ }^{35}$ among others. Methanol extraction is reported to work more efficiently for low molecular weight polyphenols. ${ }^{36}$ However, better extractability with ethanol ${ }^{37}$ and acetone ${ }^{38}$ are also reported in different plant species. The present study also reveals that TTC is extracted best in aqueous condition at $48 \mathrm{~h}$. Efficacy of aqueous extraction for TTC is also reported earlier ${ }^{23}$ suggesting more water-soluble tannins in the leaves of the plant species. Variation in the quantified amounts of different phenolic components in relation to solvent extraction may be attributed to varying solubility and the existence of a phenolic compound in different forms. ${ }^{39}$ The present study also indicates higher estimates of the phenolics mostly in SDL than FL, which is in accordance to the earlier reports. ${ }^{40}$ The higher amount of TPC in FL in most extractions is possibly due to interaction of FC reagent with interfering molecules present in higher amount in FL, causing an overestimation of total TPC. ${ }^{39,41}$ However, a reversal of such situation is noted at higher durations of methanolic and ethanolic extracts of SDL which can be the consequences of masking of interfering compounds due to higher yield of TPC.

In recent years, plant phenolics are gaining much importance for its health benefits due to their antioxidant properties. ${ }^{39}$ The present work highlights significant enhancement of TAA in SDL than FL in a time dependent manner following different solvent extractions. Such observations are also reported earlier. ${ }^{42}$ Methanol extracted samples of $P$. foetida are found superior in antioxidant activity over ethanol, acetone and water. TAA activity is found positively and significantly correlated with TPC and TFC. Similar findings are also noted in other plant taxa by earlier workers. ${ }^{34,43,44}$ On the contrary, acetone and ethanol extracts are found effective in extracting antioxidant rich fractions from banana peel ${ }^{45}$ and in Gynura leaf ${ }^{46}$ respectively.

Plant derived antioxidants are also assessed by two distinct methodsability to quench free radicals and reducing power assay. ${ }^{47}$ In the present investigation, three radical scavenging (DPPH, ABTS, SO) and one reducing power (FRAP) assay are tested for antioxidant activity of leaf extracts obtained with different solvents at $48 \mathrm{~h}$. Among all the assays, methanolic extract of SDL at $48 \mathrm{~h}$ shows higher activity over the extracts with ethanol, acetone and water. The superiority of methanol over other solvents is also evidenced for DPPH, ${ }^{43} \mathrm{ABTS}^{34} \mathrm{SO},{ }^{48}$ and $\mathrm{FRAP}^{49}$ assays in different plant species. Thus, the methanolic extractions of SDL for $48 \mathrm{~h}$ duration are superior over other conditions for extracting phenolic components with substantial antioxidant activity in $P$. foetida.

\section{CONCLUSION}

The study documents the following: (i) the leaves of $P$. foetida possesses significant amount of phenolics; (ii) methanol is the better extraction solvent than ethanol, acetone and water for TPC and TFC; TTC estimates are highest in aqueous extraction for $48 \mathrm{~h}$; (iii) the TAA estimates positively and significantly correlated with TPC and TFC indicating phenolic components, particularly flavonoids are the major contributors for antioxidant activity and (iv) the superiority of methanolic extracts is confirmed by the estimates of lower $\mathrm{IC}_{50}$ values in DPPH, ABTS and SO scavenging assays and higher estimates in FRAP assay.

The outcome of the study may be explored for identifying antioxidant rich flavonoids in $P$. foetida. Studies related to antioxidant components may provide pharmacologic importance signifying ethnomedicinal uses of the plant species.

\section{ACKNOWLEDGEMENT}

The authors are grateful to DST-PURSE, University of Kalyani and UGC (RGNF) for financial support. The authors are thankful to Prof. A.K.
Datta and Dr. S. Gupta, Department of Botany, University of Kalyani for their valuable suggestions.

\section{CONFLICT OF INTEREST}

The authors declare that there is no conflict of interest.

\section{ABBREVIATIONS USED}

TPC: Total phenolic content; TFC: Total flavonoid content; TTC: Total tannin content; TAA: Total antioxidant activity; FL: Fresh leaves; SDL: Shade dried leaves; DPPH: Diphenyl-1-picrylhydrazyl; ABTS: 2, 2'-azinobis-3-ethylbenzthiazoline-6-sulfonic acid; SO: Superoxide; FRAP: Ferric reducing antioxidant power; NBT: Nitro blue tetrazolium; TPTZ: 2, 4, 6-tripyridyl-s-triazine; CD: Critical difference.

\section{REFERENCES}

1. Chanda S, Sarethy IP, De B, Singh K. Paederia foetida - a promising ethnomedicinal tribal plant of northeastern India. J For Res. 2013;24(4):801-8.

2. Khare CP. Indian Medicinal Plants - an illustrated dictionary. Springer-Verlag. 2008.

3. Kumar V, Al-Abbasi FA, Ahmed D, Verma A, Mujeeb M, Anwar F. Paederia foetida Linn. inhibits adjuvant induced arthritis by suppression of PGE(2) and COX-2 expression via nuclear factor-кB. Food Funct. 2015:6(5):1652-66.

4. De S, Ravishankar B, Bhavsar GC. Investigation of the anti-inflammatory effects of Paederia foetida. J Ethnopharmacol. 1994;43(1):31-8.

5. Uddin B, Nahar T, Basunia MA, Hossain S. Paederia foetida protects liver against hepatotoxin-induced oxidative damage. Adv Biol Res. 2011;5(5):262-72.

6. Nosálová G, Mokry J, Ather A, Khan MTH. Antitussive activity of ethanolic extract of Paederia foetida (Rubiaceae family) in non-anaesthetized cats. Acta Vet. Brno. 2007;76(1):27-33.

7. Afroz S, Alamgir M, Khan MTH, Jabbar S, Nahar N, Choudhuri MSK. Antidiarrhoeal activity of the ethanol extract of Paederia foetida Linn. (Rubiaceae). J Ethnopharmacol. 2006;105(1):125-30.

8. Soni DK, Sharma V, Chauhan NS, Dixit VK. Effect of ethanolic extract of Paederia foetida Linn. leaves on sexual behaviour and spermatogenesis in male rats. J Men's Health. 2012;9(4):268-76.

9. Shukla YN, Lloyd HA, Morton JF, Kapadia GJ. Iridoid glycosides and other constituents of Paederia foetida. Phytochemistry. 1976;15(12):1989-90.

10. Wong KC, Tan GL. Steam volatile constituents of the aerial parts of Paederia foetida L. Flavour Fragr J. 1994;9(1):25-8.

11. Peng W, Qiu XO, Shu ZH, Liu QC, Hu MB, Han T, et al. Hepatoprotective activity of total iridoid glycosides isolated from Paederia scandens (Lour.) Merr. var. tomentosa. J Ethnopharmacol. 2015;174:317-21.

12. Shanmugam MK, Dai X, Kumar AP, Tan BKH, Sethi G, Bishayee A. Ursolic acid in cancer prevention and treatment: Molecular targets, pharmacokinetics and clinical studies. Biochem Pharmacol. 2013;85(11):1579-87.

13. Saeidnia S, Manayi A, Gohari AR, Abdollahi M. The story of beta-sitosterol- a review. European J Med Plants. 2014;4:590-609

14. Srianta I, Arisasmita JH, Patria HD, Epriliati I. Ethnobotany, nutritional composition and DPPH radical scavenging of leafy vegetables of wild Paederia foetida and Erechtites hieracifolia. Int Food Res J. 2012;19(1):245-50.

15. Kapadia GJ, Shukla YN, Bose AK, Fujiwara H, Lloyd HA. Revised structure of paederoside, a novel monoterpene S-methyl thiocarbonate. Tetrahedron Lett. 1979;20(22):1937-8

16. Dai J, Mumper RJ. Plant Phenolics: Extraction, analysis and their antioxidant and anticancer Properties. Molecules. 2010;15(10):7313-52.

17. Rice-Evans CA, Miller NJ, Paganga G. Structure-antioxidant activity relationships of flavonoids and phenolic acids. Free Radical Biol Med. 1996;20(7):933-56.

18. Azmir J, Zaidul ISM, Rahman MM, Sharif KM, Mohamed A, Sahena F, et al. Techniques for extraction of bioactive compounds from plant materials: A review. J Food Eng. 2013;117(4):426-36

19. Lapornik B, Prosek M, Wondra AG. Comparison of extracts prepared from plant by-products using different solvents and extraction time. J Food Eng. 2005:71(2):214-22.

20. Prain D. Bengal Plants (Vol.1). Calcutta and London: West, Newman and Co. 1903;577-8

21. Ainsworth EA, Gillespie KM. Estimation of total phenolic content and other oxidation substrates in plant tissues using Folin-Ciocalteu reagent. Nat Protoc. 2007:2(4):875-7.

22. Chang $C$, Yang $M$, Wen $H$, Chern J. Estimation of total flavonoid content in propolis by two complementary colorimetric methods. J Food Drug Anal. 2002;10(3):178-82.

23. Price ML, Butler LG. Rapid visual estimation and spectrophotometric determination of tannin content of sorghum grain. J Agric Food Chem. 1977;25(6):1268-73. 
24. Prieto P, Pineda M, Aguilar M. Spectrophotometric quantitation of antioxidant capacity through the formation of a phosphomolybdenum complex: specific application to the determination of vitamin E. Anal Biochem. 1999;269(2):337-41.

25. Brand-Williams W, Cuvelier ME, Berset C. Use of a free radical method to evaluate antioxidant activity. Lebensm Wiss u Technol. 1995;28(1):25-30.

26. Re R, Pellegrini N, Proteggente N, Pannala A, Yang M, Rice-Evans C. Antioxidant activity applying an improved ABTS radical cation decolorization assay. Free Radic Biol Med. 1999;26(9):1231-7.

27. Beauchamp C, Fridovich I. Superoxide Dismutase: improved assays and an assay applicable to acrylamide Gels. Anal Biochem. 1971;44(1):276-87.

28. Ravishankara MN, Shrivastava N, Padh H, Rajani M. Evaluation of antioxidant properties of root bark of Hemidesmus indicus $\mathrm{R}$. Br. (Anantmul). Phytomedicine. 2002;9(2):153-60.

29. Benzie FF, Strain JJ. The ferric reducing ability of plasma (FRAP) as a measure of "antioxidant power": The FRAP assay. Anal Biochem. 1996;239(1):70-6.

30. Upadhyaya S. Screening of phytochemicals, nutritional status, antioxidant and antimicrobial activity of Paederia foetida Linn. from different localities of Assam, India. J Pharm Res. 2013;7(1):139-41.

31. Osman H, Rahim AA, Isa NM, Bakhir NM. Antioxidant Activity and Phenolic Content of Paederia foetida and Syzygium aqueum. Molecules. 2009;14(3):970-8.

32. Azwanida NN. A review on the extraction methods use in medicinal plants, principle, strength and limitation. Med Aromat Plants. 2015;4(196):2167-0412. doi:10.4172/2167-0412.1000196.

33. Butsat S, Siriamornpun S. Effect of solvent types and extraction times on phenolic and flavonoid contents and antioxidant activity in leaf extracts of Amomum chinense C. Int Food Res J. 2016;23(1):180-7.

34. Ali IBEH, Bahri R, Chaouachi M, Boussaïd M, Harzallah-Skhiri F. Phenolic content, antioxidant and allelopathic activities of various extracts of Thymus numidicus Poir. organs. Ind Crops Prod. 2014;62:188-95

35. Siddhuraju P, Becker K. Antioxidant properties of various solvent extracts of total phenolic constituents from three different agroclimatic origins of drumstick tree (Moringa oleifera Lam.) leaves. J Agric Food Chem. 2003;51(8):2144-55.

36. Metivier RP, Francis FJ, Clydesdale FM. Solvent extraction of anthocyanins from wine Pomace. J Food Sci. 1980;45(4):1099-100.

37. Durling NE, Catchpole OJ, Grey JB, Webby RF, Mitchell KA, Foo LY, et al.
Extraction of phenolics and essential oil from dried sage (Salvia officinalis) using ethanol-water mixtures. Food Chem. 2007;101(4):1417-24.

38. Złotek U, Mikulska S, Nagajek M, Swieca M. The effect of different solvents and number of extraction steps on the polyphenol content and antioxidant capacity of basil leaves (Ocimum basilicum L.) extracts. Saudi J Biol Sci. 2016;23(5):628-33.

39. Naczk M, Shahidi F. Phenolics in cereals, fruits and vegetables: Occurrence extraction and analysis. J Pharm Biomed Anal. 2006;41(5):1523-42.

40. Sejali SNF, Anuar MS. Effect of drying methods on phenolic contents of neem (Azadirachta indica) leaf powder. J Herbs Spices Med Plants. 2011;17(2):119-31.

41. Padda MS, Picha DH. Phenolic composition and antioxidant capacity of different heat-processed forms of sweetpotato cv. 'Beauregard'. Int J Food Sci Tech. 2008;43(8):1404-9.

42. Moguel-Ordóñez YB, Cabrera-Amaro DL, Segura-Campos MR, Ruiz-Ruiz JC Studies on drying characteristic, nutritional composition, and antioxidant properties of Stevia rebaudiana (Bertoni) leaves. Int Agrophys. 2015;29(3):323-31.

43. Roby MHH, Sarhan MA, Selim KAH, Khalel KI. Evaluation of antioxidant activity, total phenols and phenolic compounds in thyme (Thymus vulgaris L), sage (Salvia officinalis L), and marjoram (Origanum majorana L) extracts. Ind Crops Prod. 2013;43:827-31.

44. Saeed N, Khan MR, Shabbir M. Antioxidant activity, total phenolic and total flavonoid contents of whole plant extracts Torilis leptophylla L. BMC Complement Altern Med. 2012;12(1):221. http://www.biomedcentral.com/1472-6882/12/221.

45. González-Montelongo R, Lobo MG, González M. Antioxidant activity in banana peel extracts: Testing extraction conditions and related bioactive compounds. Food Chem. 2010;119(3):1030-9.

46. Wan C, Yu Y, Zhou S, Liu W, Tian S, Cao S. Antioxidant activity and free radical scavenging capacity of Gynura divaricata leaf extracts at different temperatures. Pharmacogn Mag. 2011;7(25):40-5.

47. Alam MN, Bristi NJ, Rafiquzzaman M. Review on in vivo and in vitro methods evaluation of antioxidant activity. Saudi Pharm J. 2013;21(2):143-52.

48. Kumaran A, Karunakaran RJ. In vitro antioxidant activities of methanol extracts of five Phyllanthus species from India. LWT-Food Sci Technol. 2007;40(2):344-52

49. Sowndhararajan K, Kang SC. Free radical scavenging activity from different extracts of leaves of Bauhinia vahlii Wight and Arn. Saudi J Biol Sci. 2013; 20(4):319-25

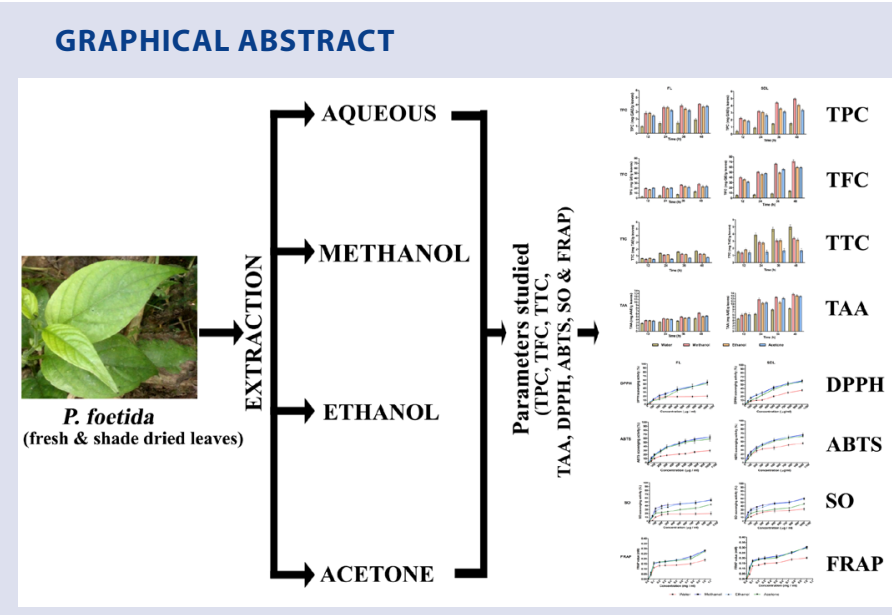

\section{SUMMARY}

- Leaf extracts of $P$. foetida contain substantial total phenolic, total flavonoid and total tannin contents.

- The yield of phenolics is higher in methanolic extractions, $48 \mathrm{~h}$ in shade dried leaves compared to fresh leaves.

- The polyphenol rich extracts manifest strong antioxidant activity.

- Total phenolics and flavonoids of $P$. foetida are important contributors for antioxidant property as evidenced from correlation analysis.

Cite this article: Ojha S, Raj A, Roy A, Roy S. Extraction of Total Phenolics, Flavonoids and Tannins from Paederia foetida L. Leaves and their Relation with Antioxidant Activity. Pharmacog J. 2018;10(3):541-7. 